\title{
Commentary: Permanent dialysis access following total artificial heart implantation: A question of maturity
}

Ashraf Abou El Ela, MD, and Paul C. Tang, MD, PhD

Renal failure requiring dialysis presents is challenging in the setting of durable mechanical circulatory support. Borgi and collegues ${ }^{1}$ reported a high 1-year mortality of $29 \%$ among patients who experienced acute renal failure after continuous-flow left ventricular assist device (cfLVAD) implant. Furthermore, $33 \%$ of the patients who required dialysis died within 1 month of cfLVAD implant. The top causes of death for the renal failure group were sepsis, right heart failure, and stroke. ${ }^{1}$ The impact of right heart failure in the setting of renal failure is not expected to play a role for total artificial heart (TAH). Permanent dialysis in patients with TAH has been previously described in several case series, and it was not surprising that achieving optimal outcomes proved elusive. ${ }^{2-4}$ For patients with a cfLVAD on dialysis, a much lower likelihood of bridging to transplant is expected. ${ }^{5}$ An important driver of this is the development of sepsis, especially when dialysis access involves foreign materials. ${ }^{5}$

Although temporary dialysis access is often used given immediate need, this presents a heightened risk of infectious complications in the longer term. Other important limitations include loss of future peripheral venous access, development of deep venous thromboses, and the occurence of embolic phenomenon. Peritoneal dialysis is also a suboptimal option given the proximity of the dialysis catheter to device drivelines and there is also a significant risk of sepsis often in the form of peritonitis. ${ }^{6}$ As Hair and colleagues ${ }^{7}$

\footnotetext{
From the Department of Cardiac Surgery, University of Michigan Frankel Cardiovascular Center, Ann Arbor, Mich.

Disclosures: The authors reported no conflicts of interest.

The Journal policy requires editors and reviewers to disclose conflicts of interest and to decline handling or reviewing manuscripts for which they may have a conflict of interest. The editors and reviewers of this article have no conflicts of interest.

Received for publication July 7, 2020; revisions received July 7, 2020; accepted for publication July 14, 2020; available ahead of print July 21, 2020.

Address for reprints: Paul C. Tang, MD, PhD, Department of Cardiac Surgery, University of Michigan, 1500 E Medical Center Dr, Ann Arbor, MI 48109-5864 (E-mail: tangpaul@med.umich.edu).

JTCVS Techniques 2020;3:225-6

2666-2507

Published by Elsevier Inc. on behalf of The American Association for Thoracic Surgery. This is an open access article under the CC BY-NC-ND license (http:// creativecommons.org/licenses/by-nc-nd/4.0/).

https://doi.org/10.1016/j.xjtc.2020.07.013
}

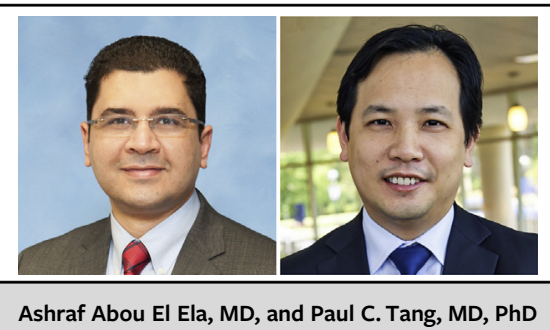

CENTRAL MESSAGE

Arteriovenous fistula access is a viable approach to minimize the sepsis risk and increase the chances of successful transplantation in patients with total artificial heart and other durable devices.

pointed out, transitioning the temporary access to an arteriovenous fistula (AVF) with avoidance of foreign material is currently the most favorable option when recovery of renal function is not anticipated. ${ }^{6}$

Readiness for AVF use is determined by its maturation and requires adequate hemodynamics. ${ }^{6}$ While the lack of pulsatility was theorized to lead to uncertainty of fistula maturation in the setting of continuous flow support, several authors have reported long-term success in this setting with excellent AVF maturation for use in dialysis. ${ }^{8-10}$ Now, Hair and colleagues ${ }^{7}$ also confirm that AVF can be successfully matured in a circulation supported by a TAH with mechanically induced pulsatile flow. It is, however, important to note that the shunt created by a mature AVF may reach 600 to $1200 \mathrm{~mL} / \mathrm{min}^{4}$ and the risk of elevating pulmonary vascular resistance should be factored into the decision to pursue an AVF in a bridge-to-transplant candidate.

While developing a mature AVF is a multistaged procedure with a heightened risk of surgical complications in the setting of chronic anticoagulation, the lowered risk of infection on device makes it seem worthwhile. Future studies on whether this will increase the success of bridging to transplantation will be facilitated by pooling cases from multiple institutions. We congratulate the authors on their successful management of this complex scenario. For durable mechanical support with bridge-to-transplant indications and endstage renal failure requiring dialysis where significant transplant wait time is anticipated, construction of an AVF is a very viable option. Maximal benefit would be gained for the patient by early consideration of this approach. 


\section{References}

1. Borgi J, Tsiouris A, Hodari A, Cogan CM, Paone G, Morgan JA. Significance of postoperative acute renal failure after continuous-flow left ventricular assist device implantation. Ann Thorac Surg. 2013;95:163-9.

2. Demiselle J, Besson V, Sayegh J, Subra JF, Augusto JF. Total artificial heart and chronic haemodialysis: a possible bridge to transplantation? Blood Purif. 2016; 42:301-3.

3. Hanna RM, Hasnain H, Kamgar M, Hanna M, Minasian R, Wilson J. Patient with a total artificial heart maintained on outpatient dialysis while listed for combined organ transplant, a single center experience. Hemodial Int. 2017;21:E69-72.

4. Quader MA, Goodreau AM, Shah KB, Katlaps G, Cooke R, Smallfield MC, et al. Renal function recovery with total artificial heart support. ASAIO J. 2016;62:87-91.

5. Topkara VK, Dang NC, Barili F, Cheema FH, Martens TP, George I, et al. Predictors and outcomes of continuous veno-venous hemodialysis use after implantation of a left ventricular assist device. J Heart Lung Transplant. 2006;25:404-8.
6. Woo K, Lok CE. New insights into dialysis vascular access: what is the optimal vascular access type and timing of access creation in CKD and dialysis patients? Clin J Am Soc Nephrol. 2016;11:1487-94.

7. Hair BB, Kirksey L, Tong MZ, Soltesz E, Hanna M. Permanent dialysis access in a patient with a total artificial heart. J Thorac Cardiovasc Surg Tech. 2020;3: 220-2.

8. Chin AI, Tong K, McVicar JP. Successful hemodialysis arteriovenous fistula creation in a patient with continuous-flow left ventricular assist device support. Am J Kidney Dis. 2017;69:314-6.

9. Khawaja A, Lim HS, Howell NJ, Inston N. Arteriovenous fistula creation in a patient without a pulse: vascular access in patients with left ventricular assist devices. J Vasc Access. 2019;20:760-2.

10. Schaefers JF, Ertmer C. Native arteriovenous fistula placement in three patients after implantation of a left ventricular assist device with non-pulsatile blood flow. Hemodial Int. 2017;21:E54-7. 